\title{
HUMAN AND PLANET CENTERED APPROACH: PROSPERITY THINKING IN ACTION
}

\author{
Vignoli, Matteo (1,2); \\ Roversi, Sara (2); \\ Jatwani, Chhavi (2); \\ Tiriduzzi, Margherita (2) \\ 1: University of Bologna; \\ 2: Future Food Institute
}

\begin{abstract}
This work aims to test Prosperity Thinking methodology in Action and assess whether this method would respond to the needs of designers, innovators, and change-makers that are willing to change the food system. Starting from the evolution of marketing design to human-centered design, we illustrate the importance of taking into account the planet's means in the design for Sustainability at the system level. We approached the problem starting from practice, with an Action Research Innovation Management Framework (Guertler, Kriz, and Sick, 2020). Results show that designers, innovators, and changemakers have an interest in a methodology that helps them to analyze and solve systemic challenges linking the micro (human) and macro (planet) through a participatory approach to achieve long-term impact of the designed solutions.
\end{abstract}

Keywords: Sustainability, Design methodology, Circular economy, Human-Centered, Prosperity

\section{Contact:}

Vignoli, Matteo

University of Bologna

Department of Management

Italy

m.vignoli@unibo.it

Cite this article: Vignoli, M., Roversi, S., Jatwani, C., Tiriduzzi, M. (2021) 'Human and Planet Centered Approach: Prosperity Thinking in Action', in Proceedings of the International Conference on Engineering Design (ICED21), Gothenburg, Sweden, 16-20 August 2021. DOI:10.1017/pds.2021.441 


\section{INTRODUCTION}

This year, the weight of all human-made artifacts has exceeded the overall living biomass on Earth (Elhacham et al., 2020). All this 'anthropogenic mass', composed of concrete, aggregates, bricks, asphalt, metals, and 'other' components (wood used for paper and industry, glass and plastic), was created for us, the humans. This results from the belief that humans are on top of an ego-system, that we can "use" our planet and shape it according to our needs. Anthropocene, a fundamental change in the relationship between humans and the Earth system (Lewis and Maslin, 2015).

All the objects and artifacts we produced are pushing Nature at the boundaries. We are crushing our planet with fundamental shifts and functioning of the Earth System, causing vast implications for natural habitats, biodiversity, and various climatic and biogeochemical cycles (Elhacham et al., 2020). We need to reverse this trend, challenging the ego-system concept toward an ecosystem where humans are and feel part of Nature.

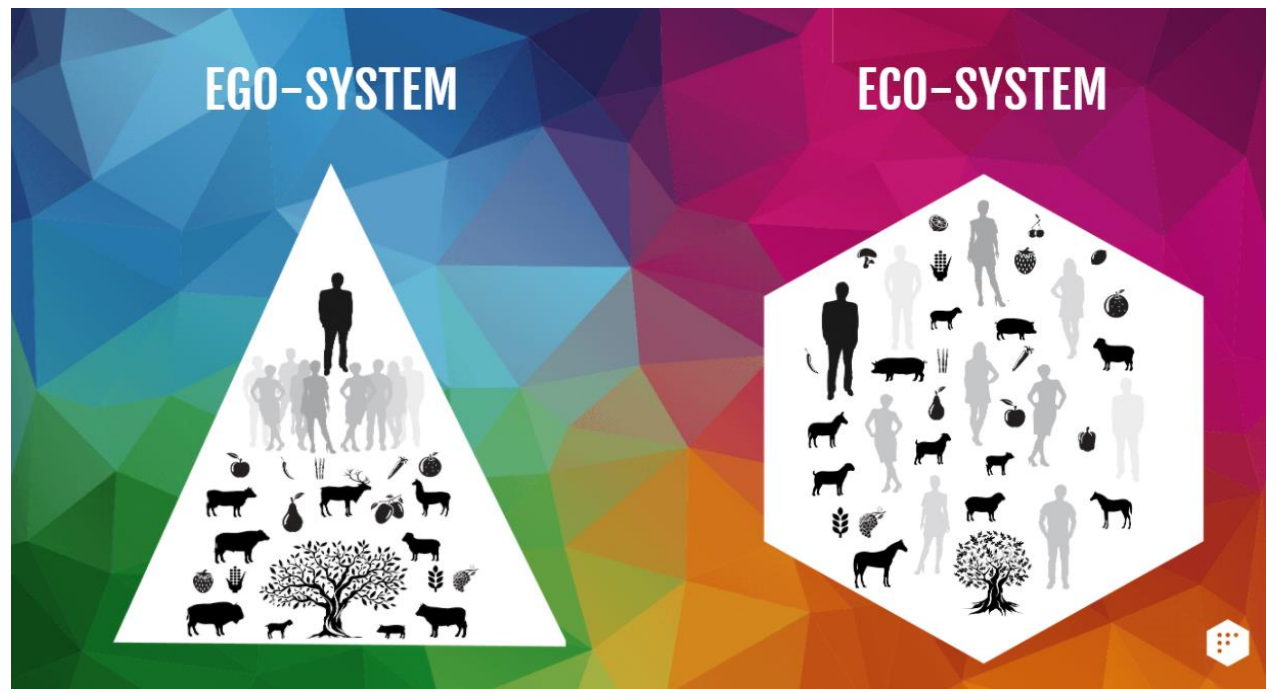

Figure 1. Ego-system and Eco-system

While producing all these artifacts, we shaped our design methods to be "human-centered", leading generations of designers to ideate objects with the purpose to please us, to serve our needs, to accommodate our desires for convenience and dominance. Luckily, design has recognized the need to reduce our impact on the planet, using sustainability concepts to reduce consumption of nonrenewable resources, minimize waste, and create healthy, productive environments (Esslinger, 2011; Vallero and Brasier, 2008; Walker, 2012). As Esslinger (2011) reminds us, we need new ideas and concepts at a systemic level to develop and achieve sustainable strategies designed with a more environmentally and economically driven vision of a better future.

In this work, we aim to outdo the current design practice, which is human-centered in nature, going beyond sustainability at a product level, to incorporate planet means right at the start of the systemic design process. Chapter 2 will examine the evolution of marketing design to Human-centered design to understand the importance of taking into account the planet's means in the designing process. This exploration made us understand the lack of an accepted methodological standard that considers sustainability in its holistic essence. We approached the problem starting from practice with an Action Research Innovation Management Framework (Guertler et al., 2020) that we describe in chapter 3. We tested in a real scenario Prosperity Thinking, a design innovation methodology we created to incorporate human needs and planetary means. To test Prosperity Thinking, we selected the food sector: its deeply interconnected identity (stakeholders, resource management, connection with consumers) and its impact on the planet makes it a prosperous and promising field to find new methodological solutions that we will present in chapters 4 and 5. This paper aims to present the development and the learnings of the methodology and assess whether this method would respond to the needs of designers, innovators, and change-makers that are willing to change the food system. 


\section{THEORETICAL BACKGROUND}

\subsection{The evolution of methodologies and mindsets in design: from Marketing thinking to Human-centered design}

Design, like nature and life, is not a static discipline but has evolved through time, becoming more and more conscious of the amplitude of its impacts on society. At the beginning of the 20th century, when the impact of the second industrial revolution was settling in, there had also been a significant improvement in the standard of living in the western world. The average per capita income was high, and we saw the birth of the modern capitalist economy. In that period, innovation was driven by technological advances, and people were buying what was marketed well to them, a phenomenon we will call 'Marketing thinking'. This was also "The Great Acceleration," or the moment when Anthropocene started (Steffen et al., 2015). As humans were becoming more central in all processes, in the 1950s, the worlds of cognitive psychology and industrial design came closer to each other, and a new realization surfaced - what people are buying is not designed for them. This paved the way for a series of human-centered and participatory practices taking the best tools from creative fields, social (like anthropology \& ethnography), and computer sciences (Information architecture \& humancomputer interaction) (Szczepanska, 2019).

The human-centered approach came to the mainstream of the business world much later in the ' $90 \mathrm{~s}$ with the popularization of 'design thinking'. This new approach to design also developed careful listening towards people's needs: empathic listening becomes essential in design processes. An example of Liz Sander's work is creating tools and methods based on human-centered design: (e.g., Maketools, a tool for co-creation and co-design). Design thinking applications in business, academia, and design are numerous and increasing in the latest years (Micheli et al., 2019).

\subsection{The importance of taking into account the planet's means}

Design was born as a discipline to tackle needs. The question that we would like to ask is: whose needs? Considering only local and specific human needs in design processes has left the planet behind and overshot its boundaries. Making clean water accessible to everyone created enormous quantities of non-biodegradable plastic waste that are nowadays reversing in the oceans, polluting entire natural systems, and coming back in our plates and bodies. Is it possible to reverse this thinking, also putting the planet in the process?

More and more consumers are becoming aware of their environmental footprint. In the US, the percentage of consumers looking for eco-friendly products rose to $49 \%$. Planet's finite resources are slowly entering consumers' consciousness and in the world of Design and become part of the designing process (Mattson, 2020).

In this perspective, in 2011, the Danish Designers claimed in its manifesto that Design should answer the "people, profit, and planet's" needs (Valade-Amland, 2011). "Design is a source of attractiveness and meaningful relationships," and it is at the center of critical processes such as the choice of materials (Valade-Amland, 2011).

\subsection{Design for Sustainability at systems' level: linking micro and macro}

Designers started taking into account the idea of sustainability in the ' 70 , with Victor Papanek and Buckminster Fuller as the two pioneers. Since then, Design for Sustainability has seen a remarkable evolution: from product innovation level, it became more and more complex passing through ProductService System innovations, Spatio-Social and Socio-Technical innovation levels (Ceschin and Gaziulusoy, 2016). Socio-technical systems, born from Eric Trist's theory (Trist, 1981), are a valuable unit of analysis when it comes to complex systems and interactions. An essential limitation of today's socio-technical systems is that they are looking at a "too 'big picture' and need to be supported by approaches that focus on developing products and services that can be part of new socio-technical systems" (Ceschin and Gaziulusoy, 2016, p. 141). Therefore, it is needed to "develop theoretical insights and practical tools to link micro-innovation with macro-innovation" (Ceschin and Gaziulusoy, 2016, p.141). Some opportunities have been identified (Savaget et al., 2019) in enhancing sociotechnical systems. From a sustainability perspective, it is crucial to take into consideration that the definition of sustainable development is vague and it accommodates a variety of understandings and expectations for progress and allows for heterogeneous responses to diversity and complexity of challenges faced by 
humans around the world (Kates et al., 2005). Therefore it is necessary to qualify better the theoretical framework in which a project is undertaken using potential questions such as:

- Who: how different are the interpretations of business people and policymakers?

- Where: how do these interpretations differ across low, middle, and high-income countries?

- When: are these interpretations changing since the Brundtland (1987) report, who first used the term sustainable development?

The evolution of these methods, passing from a product-centered approach to a more systemic one, also saw the beginning of the design methods' opening to social implications. Design agencies are working to include finite planet resources into the design process as in "Planet-centric design" from VINCIT. Ezio Manzini's work is grounded in participatory design for sustainability (Vezzoli and Manzini, 2008). "Participation is a fundamental process, not only for democracy but also for learning” (Bødker et al., 2000, p.7). As we slowly understand, the only way to change the system is by joining forces and working together at the micro and macro level toward a common goal. Participation means gaining consciousness for everybody. Systemic thinking (Acaroglu, 2019) can help us understand how systems are structured and how they work. It can help us acknowledge complexity, finding trade-offs, and make efforts to reflect on local and tailored solutions. Unsustainability plays on different levels and layers, and we need methodologies that help us understand them all together and understand the link between them to act more consciously.

\subsection{The Food sector as a pioneer sector for a new planet-centered methodology}

Recent attention has been given to the food sector thanks to the European policy From Farm to Fork (EU, 2020). Food is the first-ever product of humanity. Today, it is responsible for one-quarter of the world's greenhouse gas emissions (Clune et al., 2017). Improving the food system means improving the planet. An exemplar challenge is the use of chemical pesticides and fertilizers: the initial purpose was one to improve agriculture and get more from the same plot of land, but nowadays, intensive nonsustainable agriculture has degraded vast areas, including the contamination of soils through excessive use of inorganic fertilizers and pesticides (Dury et al., 2019).

On the other hand, food is a sector that clearly includes and deeply links the micro and macro, the humans and the planet. The interrelation between these two makes it the ideal candidate to explore a new methodology for human and planet-centered design. It is not about leaving people's needs behind but accompanying people in the design process to understand what is planet-friendly.

\section{METHODOLOGY}

This study aims to test in practice Prosperity Thinking, a Design Innovation methodology created to incorporate human needs and planetary means. We used an Action Research Innovation Management Framework (Guertler et al., 2020).

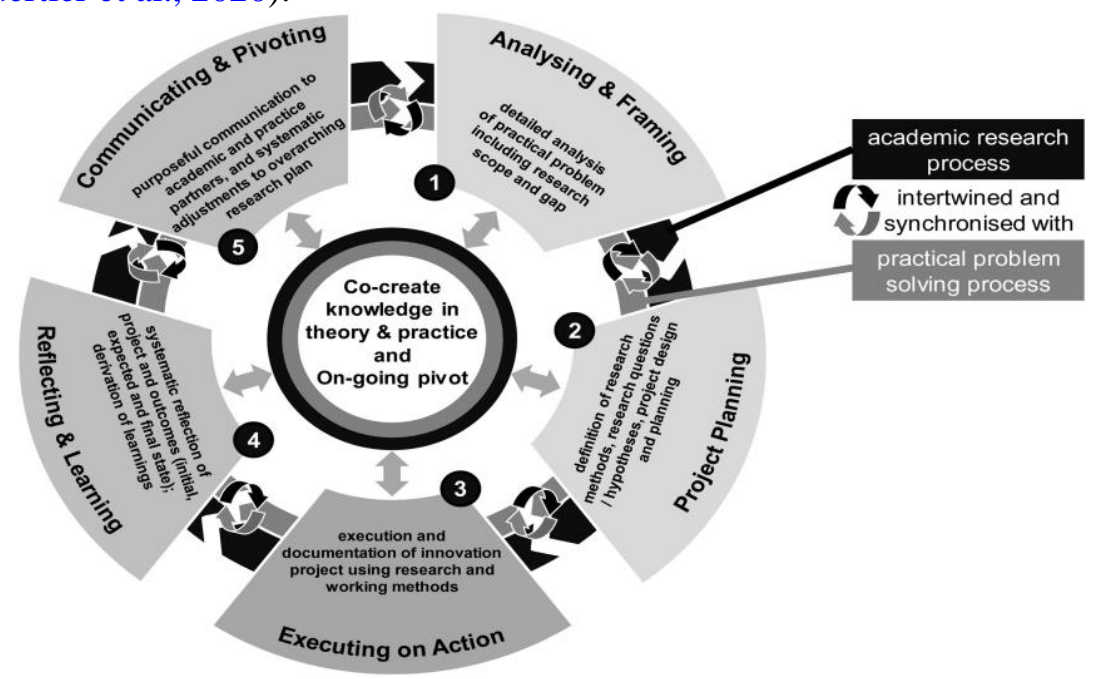

Figure 2. AIM-R framework (Guertler et al., 2020)

We followed the five circular phases provided in the AIM-R framework. We started with an (1) analysis and framing of the evolution of design innovation methodologies until human-centered design, 
identifying an opportunity to link the micro and macro level of innovation at systems' design level (§ 2.3). Literature is still underdeveloped regarding Design for Sustainability methodologies that would link micro and macro levels of innovation, therefore incorporating both human and planet perspectives from the start. As described in $\$ 2.4$, we perform (2) project planning by identifying a relevant field to initiate our action. Out of all possible fields, we identified the food sector as the best candidate to start prototyping such a methodology since it is intimately human-centered and has significant implications for our planet. We develop Prosperity Thinking ( $\$ 4)$ as a candidate methodology to be tested in foodrelated innovation projects. Next, we focused on (3) execution of the action with two prototypes of the methodology in the context of FAO and Future Food Institute boot camps. We applied the methodology in a hackathon and a workshop. During the execution, the authors were involved as conductor and participant observers. The authors analyzed all the material during the (4) reflection and learning phase. With this preliminary work, we are conducting the (5) communication and pivoting phase. We collected 40 hours of observation, field notes, a survey to workshop and hackathon participants, 11 semi-structured interviews, one focus group of 3 hours transcribed verbatim. All the meetings to develop Prosperity Thinking, as discussions and reflections on the prototypes were documented with minutes and archived (Arieli et al., 2009).

\section{PROSPERITY THINKING}

Prosperity thinking is a methodological approach to designing a world that fulfills all its beings' needs within the planet's ecological means. It aims to enable the design of a better world, starting from a shared, inclusive idea of prosperity that encompasses economic growth and social and environmental well-being. It aims to be an evolution of Design Thinking, going beyond user-centered design to human and planet-centered growth. This methodology is under development at Future Food Institute since 2019.

Prosperity Thinking aims to link together micro-innovation and macro-innovation, accompanying practitioners into a complex understanding of an ecosystem and proposing solutions at the core of the problem. To connect the micro and the macro, Prosperity Thinking was inspired by The Doughnut Model, designed by Kate Raworth (2017). We share with this approach the idea that there is a green zone for innovation with the social foundation as a lower boundary and as an upper boundary the ecological ceiling. Anything below the social boundary will damage or will not be accepted by humans resulting in waste; anything above the planetary boundary will damage our planet. We are overstepping these boundaries and falling short on some social foundations like hunger, and we need to fix this through a thoughtful design.

Prosperity Thinking seems to be very close in terms of values to Design for Sustainable Behaviour, promoting a shift in mindset towards more sustainable behaviors. It is conceived to be applied to the food sector, but differently from Design for Sustainable behavior, Prosperity Thinking aims to tackle the entire food system and not a single product. Through participatory design, we consider the entire food system, involving different participants: from the academic world to the enterprise and NGOs. In order to better understand the implications of Prosperity Thinking, we are conducting applications and experimentations. As Prosperity Thinking is under development, our research purpose was to assess whether this method would respond to the needs of designers, innovators, and change-makers that are willing to change the food system, providing an effective way to conceptually link the micro (humans) with macro (planet) through community engagement.

\subsection{Prosperity Thinking Process}

The core evolution of design thinking to prosperity thinking is noticed in the way challenges are reframed. In the discovery phase of a project, participants are asked to analyze a planet crisis revealing the human needs that drove us beyond a specific planetary boundary. Participants then create a howwe-might statement that embeds the planets' means right next to the human needs. Once this 'green zone of innovation' has been set, creativity is unleashed. We ideate, co-design, prototype, and test with contextual stakeholder communities. These stakeholders become the perfect ambassadors of prosperity-driven innovation, expanding a prosperity innovator's role into a systemic change agent, linking the micro and the macro. Chosen prototypes go through an impact analysis reflection to minimize or eliminate any long-term negative repercussions. This step helps us innovate for sustainable long-term systemic solutions. 


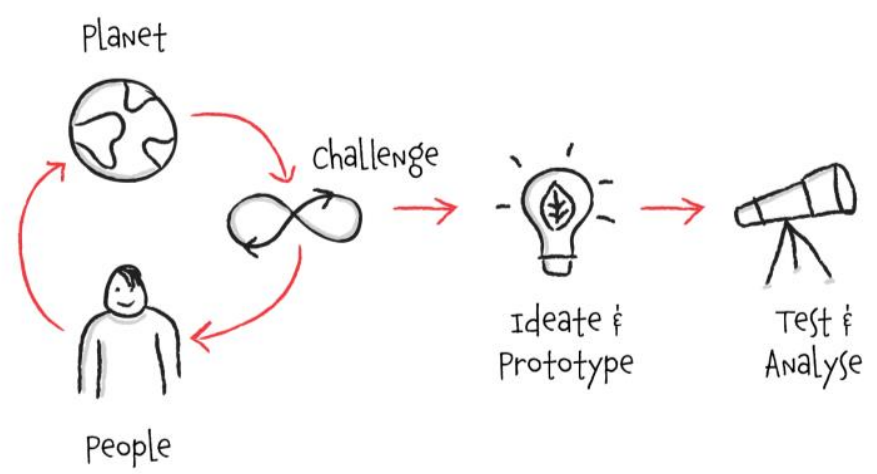

Figure 3. Prosperity thinking process

\subsubsection{Workshop}

A $1.5 \mathrm{hr}$ Prosperity Thinking workshop is a short module that explains the origin of the methodology, the values and mindset it sits on, and demonstrates the core of human and planet-centered innovation in a hands-on manner.

Table 1. Prototype of a 1 hours 30 min prosperity thinking workshop

\begin{tabular}{|c|c|c|c|}
\hline Time & Activity & Goals & Tools \\
\hline 20 mins & Motivation & $\begin{array}{c}\text { Failure of Human-centered, rise of planet } \\
\text { centered }\end{array}$ & \\
\hline 15 mins & Process & What is prosperity thinking & \\
\hline $15 \mathrm{mins}$ & $\begin{array}{l}\text { Activity 1: } \\
\text { Mindset }\end{array}$ & $\begin{array}{l}\text { Explain prompt (5 mins) }+ \text { breakout room }(10 \\
\text { mins })\end{array}$ & Iceberg Model \\
\hline 15 mins & $\begin{array}{l}\text { Activity 2: } \\
\text { Challenge }\end{array}$ & $\begin{array}{l}\text { Explain prompt (5 mins) }+ \text { breakout room (10 } \\
\text { mins })\end{array}$ & $\begin{array}{l}\text { Prosperity problem } \\
\text { statement }\end{array}$ \\
\hline 15 mins & $\begin{array}{l}\text { Activity 3: } \\
\text { Change }\end{array}$ & $\begin{array}{c}\text { Explain prompt (5 mins) }+ \text { breakout room (10 } \\
\text { mins) }\end{array}$ & $\begin{array}{l}\text { Reverse Iceberg } \\
\text { Model }\end{array}$ \\
\hline 10 mins & $\begin{array}{l}\text { Presentation and } \\
\text { Discussion }\end{array}$ & $\begin{array}{l}\text { Consolidate the use of tools and assess } \\
\text { understanding of Prosperity Thinking }\end{array}$ & $\begin{array}{l}\text { Miro Board with } \\
\text { Final Output }\end{array}$ \\
\hline
\end{tabular}

\subsubsection{Prosperity Thinking Hackathon}

Prosperity thinking hackathons (online \& offline) are held at the end of an immersive week of multistakeholder conversations about sustainable development in food systems. They start by researching and analyzing the problem space through human-centered participatory approaches merged with systems thinking tools (like causal loop and iceberg model) that converge into a prosperity problem statement. Ideation begins by drawing system maps and storyboards of potential solutions tested with stakeholder communities and analyzed through future scenario projection. A systemic solution is selected to be developed into a presentation deck of prosperity-based innovation.

Table 2. Prototype of 3 days prosperity thinking hackathon

\begin{tabular}{|c|c|c|c|}
\hline Day & $\begin{array}{c}\text { Design } \\
\text { activities }\end{array}$ & Goals of the day & $\begin{array}{c}\text { Suggested tools } \\
\text { for the } \\
\text { innovation team }\end{array}$ \\
\hline & & $\begin{array}{c}\text { One week of lessons about prosperity thinking, systems } \\
\text { theory, UN SDGs, being exposed to best practices in the } \\
\text { food systems, being part of multi-stakeholder debates } \\
\text { with representatives of institutions like the European } \\
\text { Commission and GFAR }\end{array}$ & $\begin{array}{c}\text { •Visits } \\
\text {-Lessons } \\
\text { •Debates }\end{array}$ \\
\hline 1 & Kick-off & Get introduced to the challenge & \\
\hline 1 & Context & $\begin{array}{c}\text { Interview a diverse set of stakeholders, from primary } \\
\text { mapping } \\
\text { the complete ecosystem of the problem space and how } \\
\text { different factors influence each other }\end{array}$ & $\begin{array}{c}\text { brain map } \\
\text { causal loop }\end{array}$ \\
\hline
\end{tabular}




\begin{tabular}{|c|c|c|c|}
\hline 1 & $\begin{array}{l}\text { Research \& } \\
\text { People \& } \\
\text { Planet need } \\
\text { definition }\end{array}$ & $\begin{array}{l}\text { Identify human-centered needs } \\
\text { Identify the planetary boundaries associated with the } \\
\text { context } \\
\text { Opportunity statement definition to begin the ideation }\end{array}$ & $\begin{array}{l}\text { Prosperity } \\
\text { Problem } \\
\text { statement }\end{array}$ \\
\hline 2 & $\begin{array}{l}\text { Ideation \& } \\
\text { Prototyping }\end{array}$ & $\begin{array}{l}\text { Generation of a wide range of diverse ideas and a } \\
\text { combination of ideas to be applied on a systems level } \\
\text { Test concepts and co-design with the community and } \\
\text { stakeholders to get them invested in the opportunity } \\
\text { space }\end{array}$ & $\begin{array}{l}\text { Storyboard, } \\
\text { system maps }\end{array}$ \\
\hline 2 & $\begin{array}{l}\text { Testing \& } \\
\text { community } \\
\text { creation }\end{array}$ & $\begin{array}{l}\text { Test concepts and co-design with the community and } \\
\text { stakeholders to get them invested in the prosperity space } \\
\text { to create multi-stakeholder systemic innovation }\end{array}$ & $\begin{array}{l}\text { Interviews, } \\
\text { focus groups }\end{array}$ \\
\hline 3 & Refinement & $\begin{array}{c}\text { study and plot the financial feasibility } \\
\text { identify and test different financial feasibility models }\end{array}$ & $\begin{array}{l}\text { Purpose-driven } \\
\text { canvas }\end{array}$ \\
\hline 3 & $\begin{array}{l}\text { Analyze, } \\
\text { Roadmap }\end{array}$ & $\begin{array}{c}\text { Map potential impact areas trying to project } 5,10,20 \\
\text { years down the line. Look for potential negative } \\
\text { externalities and tweak the concept } \\
\text { Definition of the implementation roadmap }\end{array}$ & \\
\hline 3 & $\begin{array}{c}\text { Final } \\
\text { presentation }\end{array}$ & & \\
\hline
\end{tabular}

\section{RESULTS}

In order to test our methodology, we used Prosperity Thinking on three online workshops and two hackathons (one online and one in presence) organized by Future Food Institute, a center of excellence for food intelligence and a training platform for changemakers, climate shapers, and future leaders in the food innovation ecosystem.

The Prosperity Thinking workshops (1h30) were an activity included in the Digital Bootcamp, an online experience in which participants can debate and interact around sustainability topics with various sectors' experts. Participants were asked to analyze unsustainable events starting from news articles (i.e., events that pollute the environment or cause social disparities) and, using the Iceberg model, reframing the challenge with a prosperity problem statement, and ideate solutions for it with the reversed Iceberg model. We involved 129 participants who were applying Prosperity Thinking in the three workshops. The participants were 13 to 64 years old with a very diverse background (e.g. startuppers, business executives, activistis, designers, CEOs, and students). They came from 47 countries and diverse fields such as social sciences, agronomy, food innovation, engineering, food service, mathematics, and linguistics.

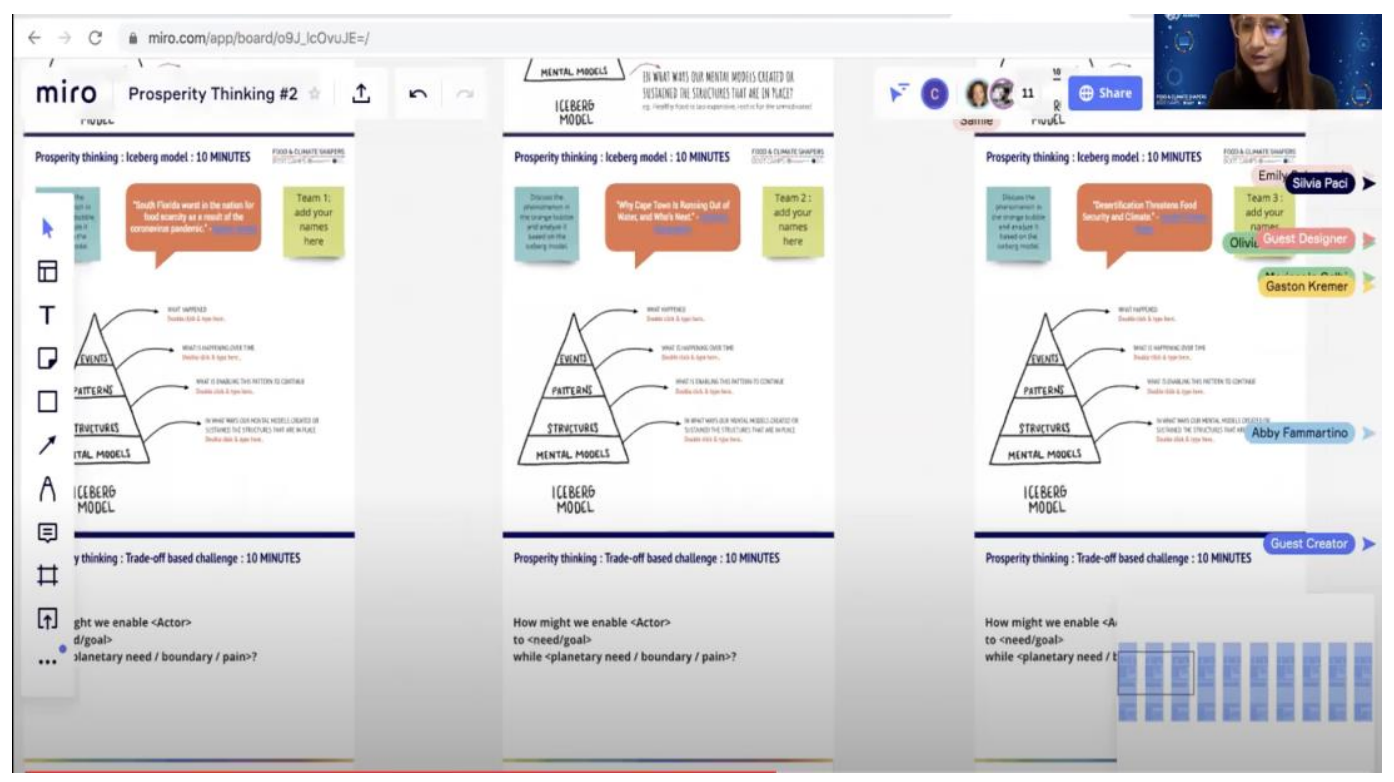

Figure 4. Workshop digital board 
During the Prosperity Thinking Hackathon, participants were given a challenge from an organization. They researched and analyzed the context through interviews with the local community (e.g., Mayor, restaurant owners, shopkeepers) and created prosperity problem statements. Then, they ideated potential solutions, tested them with the stakeholders, and prepared a pitch deck representing their idea for the partner organization. We had 39 participants involved in 8 projects for the in-presence hackathon, and for the online hackathon, 129 participants involved in 24 projects using Prosperity Thinking. Coaches from Future Food Institute helped the innovation process and helped the teams support their research and ideation. The in-presence Hackathon was partnering with Barilla, a global food manufacturer, and the online hackathon was partnering with FAO, the Food and Agriculture Organization of the United Nations.

The insights that we found are related to the Prosperity Thinking workshop and the Hackathon. The information we were looking for was a general understanding of how the participants perceive the Prosperity Thinking values, methodology and how it helps their professional and personal lives. To better understand our experimental methodology's impact and pull out the main initial outcomes, we performed a structured online survey to collect students' feedback with 57 answers out of 127 participants. We conducted eleven qualitative interviews with voluntary participants, and finally, we conducted one focus group with three participants and four organizers, using Tim Strasser's 3D impact assessment tool (Strasser et al., 2020). The data and insights that follow are a result of these three assessments.

The online quantitative survey was structured into different sub-parts, asking this question for each part "To what extent did the boot camp help you acquire the following knowledge, tools, skills, and mindsets?" (rating was on a scale from 1 to 5): Understanding complex systems - 4.04; Ecosystem thinking (ability to connect the dots) - 4.54; Prosperity thinking (Human \& planet centered development) - 4.54; Design thinking - 4.24; Ability to drive community action - 4.04.

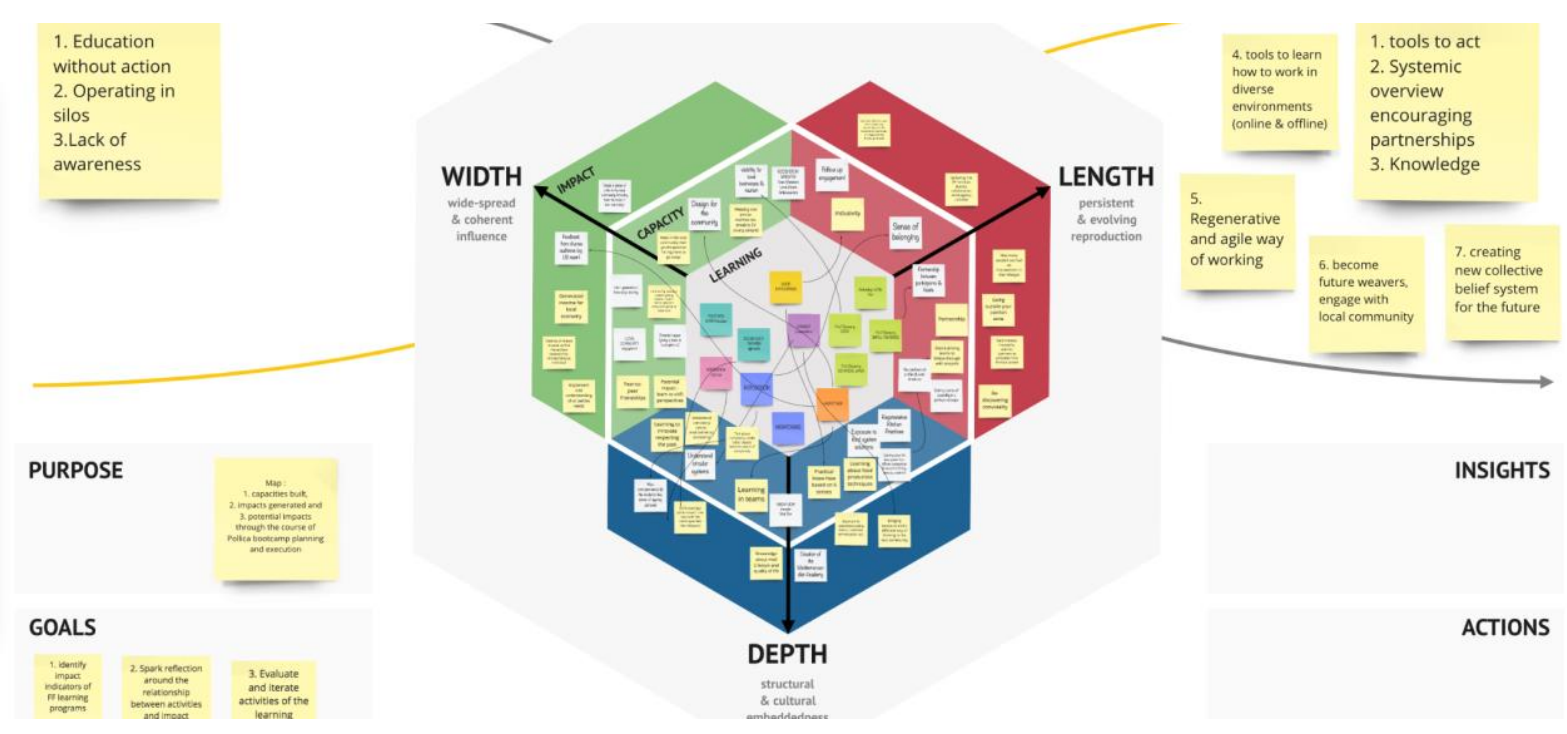

Figure 5. Tim strasser's 3D impact assessment tool used during focus group activity

Analyzing the transcription of the interviews and focus group, we identified some key aspects. Most participants agreed that a clear need for a methodology connects micro and macro, humans and planet. For instance, Jeff, a climate shaper, mentioned: "The revolutionary philosophy of prosperity thinking is imperative to the functionality of an SDG-driven business world.". The methodology's aim was immediately apparent to most people from the very start, highlighting an alignment on a world vision that promotes collaboration to solve systemic issues. Anna, a food change activist, reported: "I learned the value of intergenerational collaboration". Many participants felt inspired to act on their local ecosystem to face systemic problems. Abby, senior food manager, concluded, "This activity set things in motion for me, where before I felt stagnant and unsure where to direct my energy, education, and talents. I feel inspired and more directed and prepared to think and work in a practical, futurelooking way."

While thinking about putting Prosperity Thinking in motion, others needed more support to map and identify contextual planetary boundaries. Gesina, an innovation project manager, asked, "How and 
where can I find an understanding of planetary boundaries that I should consider in my project?". In leveraging communities, it is critical to connecting with diverse stakeholders from various backgrounds. Dieume, a university student, claimed, "To make a change, you need to reach out to everyone in the community". When thinking about implementing systemic change, many recognized that systems are not designed to be agile; therefore, proper systemic solutions become hard to be implemented. Arina, a chef interested in implementing the results of the Hackathon, reported: "I learned about the systemic approach to executing ideas and working one step at a time no matter how small."

\section{DISCUSSIONS AND CONCLUSIONS}

Given our work's preliminary and exploratory nature, we could not expect solid validation, but instead, we were looking for insights and directions to move forward. In this line, we were delighted to notice a general interest in Prosperity Thinking by all the Workshop and Hackathon participants. The average judgment about acquired knowledge on Prosperity Thinking after our experiences was relatively high, scoring 4.5 out of 5. A participant in the Workshop stated, "this approach was so interesting that I decided to join the session for the other timezone, even if it is the deep night in my geography". This was validating the interest in this methodology from designers, innovators, and change-makers operating in the food sector.

Both the Prosperity Workshop and Hackathon contain a theoretical part where the participants are exposed to sustainability-related content through a diverse set of industry experts. Participants are inspired by these conversations and jump into action during the teamwork. This combination 'sets things in motion' and helps students understand which can be their entry point to start solving for sustainability in their communities.

The complexity of identifying and mapping the planetary boundaries to focus on within a given challenge was apparent when some teams struggled to create their prosperity problem statement. It will be critical to better design this initial phase in order to guide the participant to choose a combination of human need and planetary boundary relevant to the hackathon scope.

Participants recognized the potential link between micro (human) and macro (planet) with a systemic approach involving engaging communities and diverse stakeholders. However, we cannot assume that a 13-year-old and 64-year-old participant or an artist and a policymaker can communicate and collaborate effectively without any facilitation. Therefore a prosperity thinking facilitator must have the proper instruments of participatory design, and the method should foresee simple, tangible tools to aid these conversations. We know complex problems need systemic solutions, but our systems are mammoths. Systems innovation by linking macro with micro needs more experimentation to validate if it is possible to bring systems-wide shift through grass-roots activities like prosperity-driven innovation.

Systems thinking has been identified as an effective means to analyze and solve planetary challenges. Future Research will deepen our knowledge of the field and identify more tools to value the planetary boundaries and link micro and macro, as the human side is already developed in current methodologies. Developing Prosperity Thinking further takes from purpose-driven leadership to develop innovators and real changemakers who can engage communities and drive prosperity-based innovation through the participatory and systemic processes in complex projects. Gesina, an innovation project manager, was ready to put learning into practice: "this foundation was unique and so inspiring to experience. I would love to continue this learning experience [...] to put the learning into practice with real-life examples". However, changing the approach to design for sustainability at the system level requires more than a new method. It requires sharing the fundamental mindset and values that drive our behavior toward a better planet. Developing further Prosperity Thinking is our starting point towards this change journey.

\section{REFERENCES}

Acaroglu, L. (2019), “Tools for Systems Thinkers: The 6 Fundamental Concepts of Systems Thinking”, Medium, 7 October, available at: https://medium.com/disruptive-design/tools-for-systems-thinkers-the-6fundamental-concepts-of-systems-thinking-379cdac3dc6a (accessed 8 December 2020).

Arieli, D., Friedman, V.J. and Agbaria, K. (2009), "The paradox of participation in action research", Action Research, SAGE Publications, Vol. 7 No. 3, pp. 263-290. https://doi.org/10.1177/1476750309336718

Bødker, S., Ehn, P., Sjögren, D. and Sundblad, Y. (2000), “Co-operative Design—perspectives on 20 years with 'the Scandinavian IT Design Model'”, Proceedings of NordiCHI, Vol. 2000, pp. 22-24. 
Ceschin, F. and Gaziulusoy, I. (2016), "Evolution of design for sustainability: From product design to design for system innovations and transitions", Design Studies, Vol. 47, pp. 118-163. https://doi.org/10.1016/j.destud.2016.09.002

Clune, S., Crossin, E. and Verghese, K. (2017), "Systematic review of greenhouse gas emissions for different fresh food categories", Journal of Cleaner Production, Vol. 140, pp. 766-783. https://doi.org/10.1016/j.jclepro.2016.04.082

Dury, S., Bendjebbar, P., Hainzelin, E., Giordano, T. and Bricas, N. (Eds.). (2019), Food Systems at Risk. New Trends and Challenges, FAO; CIRAD, Rome, Italie. https://doi.org/10.19182/agritrop/00080.

Elhacham, E., Ben-Uri, L., Grozovski, J., Bar-On, Y.M. and Milo, R. (2020), “Global human-made mass exceeds all living biomass", Nature, Nature Publishing Group, pp. 1-3. https://doi.org/10.1038/s41586-020-3010-5

Esslinger, H. (2011), "Sustainable Design: Beyond the Innovation-Driven Business Model”, Journal of Product Innovation Management, Vol. 28 No. 3, pp. 401-404. https://doi.org/10.1111/j.1540-5885.2011.00811.x

EU. (2020), From Farm to Fork, available at: https://eur-lex.europa.eu/legalcontent/EN/TXT/?uri=CELEX:52020DC0381.

Guertler, M.R., Kriz, A. and Sick, N. (2020), "Encouraging and enabling action research in innovation management”, R\&D Management, Vol. 50 No. 3, pp. 380-395. https://doi.org/10.1111/radm.12413

Kates, R.W., Parris, T.M. and Leiserowitz, A.A. (2005), "What is Sustainable Development? Goals, Indicators, Values, and Practice", Environment: Science and Policy for Sustainable Development, Routledge, Vol. 47 No. 3, pp. 8-21. https://doi.org/10.1080/00139157.2005.10524444

Lewis, S.L. and Maslin, M.A. (2015), "Defining the Anthropocene", Nature, Nature Publishing Group, Vol. 519 No. 7542, pp. 171-180. https://doi.org/10.1038/nature14258

Mattson, I. (2020), “COVID-19 F\&B Industry Study Results”, 1 April, available at: https://www.preparedfoods.com/ext/resources/PDF/Mattson_Industry_Sentiment_Survey.pdf (accessed 8 December 2020).

Micheli, P., Wilner, S.J.S., Bhatti, S.H., Mura, M. and Beverland, M.B. (2019), "Doing Design Thinking: Conceptual Review, Synthesis, and Research Agenda", Journal of Product Innovation Management, Vol. 36 No. 2, pp. 124-148. https://doi.org/10.1111/jpim.12466

Raworth, K. (2017), Doughnut Economics: Seven Ways to Think like a 21st-Century Economist, Chelsea Green Publishing.

Savaget, P., Geissdoerfer, M., Kharrazi, A. and Evans, S. (2019), "The theoretical foundations of sociotechnical systems change for sustainability: A systematic literature review”, Journal of Cleaner Production, Vol. 206, pp. 878-892. https://doi.org/10.1016/j.jclepro.2018.09.208

Steffen, W., Broadgate, W., Deutsch, L., Gaffney, O. and Ludwig, C. (2015), "The trajectory of the Anthropocene: The Great Acceleration", The Anthropocene Review, SAGE Publications, Vol. 2 No. 1, pp. 81-98. https://doi.org/10.1177/2053019614564785

Strasser, T., de Kraker, J. and Kemp, R. (2020), "Three Dimensions of Transformative Impact and Capacity: A Conceptual Framework Applied in Social Innovation Practice”, Sustainability, Multidisciplinary Digital Publishing Institute, Vol. 12 No. 11, p. 4742. https://doi.org/10.3390/su12114742

Szczepanska, J. (2019), "Design thinking origin story plus some of the people who made it all happen”, Medium, 2 June, available at: https://medium.com/@ szczpanks/design-thinking-where-it-came-from-and-the-type-ofpeople-who-made-it-all-happen-dc3a05411e53 (accessed 8 December 2020).

Trist, E.L. (1981), The Evolution of Socio-Technical Systems, Vol. 2, Ontario Quality of Working Life Centre Toronto.

Valade-Amland, S. (2011), "Design for People, Profit, and Planet”, Design Management Review, Vol. 22 No. 1, pp. 16-23. https://doi.org/10.1111/j.1948-7169.2011.00106.x

Vallero, D.A. and Brasier, C. (2008), Sustainable Design: The Science of Sustainability and Green Engineering, John Wiley \& Sons.

Vezzoli, C. and Manzini, E. (2008), Design for Environmental Sustainability, Springer.

Walker, S. (2012), Sustainable by Design: Explorations in Theory and Practice, Routledge. 